\title{
Histology and Morphology of Asparagus Somatic Embryos
}

\author{
A. Levi' and K.C. Sink \\ Department of Horticulture, Michigan State University, East Lansing, \\ MI 48824
}

Additional index words. Asparagus officinalis, embryogenesis, tissue culture

Abstract. The histology and morphology of developing asparagus Asparagus officinalis L.) somatic embryos arising in callus cultures were examined and contrasted with that documented for zygotic embryos. Histological sections of lateral bud-derived callus cultured for 2 weeks on embryo induction medium consisting of Murashige and Skoog salts and vitamins (MS) with $1.5 \mathrm{mg}$ NAA/liter and $0.1 \mathrm{mg}$ kinetin/liter indicated the formation of distinct groups of embryogenic cells. At 4 weeks, the callus was comprised of embryos in the early and late globular stages and a few bipolar embryos. Within 2 weeks on embryo development medium consisting of MS with $0.05 \mathrm{mg}$ NAA/liter and $0.1 \mathrm{mg}$ kinetin/liter, the globular embryos developed a bipolar shape having an expanded upper region that formed the cotyledon and a smaller region that formed the radicle. Within 4 to 6 weeks on this latter medium, each mature bipolar embryo was opaque and had a large cotyledon, a distinct shoot apex at the cotyledon-hypocotyl junction, and vascular connections between the radicle, shoot apex, and cotyledon. Many mature somatic embryos resembled the asparagus zygotic embryos in having a crescent shape, whereas others had a short but wide cotyledon. Both somatic embryo types converted to plantlets at equal rates. Chemical names used: $N$ - (2-furanylmethyl)$1 \mathrm{H}$-purin-6-amine (kinetin); 1-naphthaleneacetic acid (NAA).

Asparagus has a low multiplication rate using conventional propagation methods (Yang and Clore, 1973). Tissue culture experiments have proved to be successful, and asparagus is one of the first monocot species to be regenerated to somatic embryos and plantlets in vitro (Reuther, 1977; Steward and Mapes, 1971; Wilmar and Hellendoorn, 1968). However, the developmental sequence of in vitro-derived somatic embryos has not been histologically detailed nor contrasted to that of asparagus zygotic embryos (Riviere, 1973). To date, only the gross morphology of the crescent-shaped somatic embryo stage (Bui Dang Ha et al., 1975) and a schematic pattern of the multicellular origin of embryos (Reuther, 1983) have been reported. Recently, we demonstrated that calli derived from lateral buds and crowns in vitro had a higher embryogenic capacity than calli derived from spear sections (Levi and Sink, 1991). Additionally, NAA promoted a higher frequency of normal somatic embryos than did 2,4-dichlorophenoxyacetic acid (2,4-D). This report examines the developmental sequence of asparagus somatic embryos formed

Received for publication 2 Jan. 1991. The cost of publishing this paper was defrayed in part by the payment of page charges. Under postal regulations, this paper therefore must be hereby marked advertisement solely to indicate this fact.

${ }^{1}$ Present address: Dept. of Horticulture, Univ. of Georgia, Athens, GA 30602. in lateral bud-derived calli and contrasts it with that already known for asparagus zygotic embryos.

Lateral buds (1 to $2.5 \mathrm{~cm}$ long) were obtained from the upper portion of 4- to 7-dayold spears of a male asparagus crown selection (M.S.U. C-3) grown in the greenhouse. Spears were surface sterilized for $30 \mathrm{~min}$ in aqueous sodium hypochlorite $(1.5 \% \mathrm{w} / \mathrm{v})$ solution with $0.05 \%$ Tween 20 . Subsequently, spears were rinsed three times with sterile distilled water.

To initiate callus, three lateral buds were placed in each of ten $15 \times 100-\mathrm{mm}$ petri dishes. Each petri dish contained $25 \mathrm{ml}$ of culture medium: Murashige and Skoog (1962) (MS) with $0.1 \mathrm{mg} \mathrm{NAA} /$ liter and $0.01 \mathrm{mg}$ kinetin/liter. Within 4 weeks, primary calli were separated from the explants and subculture twice at 4-week intervals. Subsequently, calli were transferred to MS medium with $1.5 \mathrm{mg} \mathrm{NAA} / \mathrm{liter}$ and $0.1 \mathrm{mg}$ kinetin/ liter (embryo induction medium). Following 4 weeks on induction medium, calli were transferred to MS medium with $0.05 \mathrm{mg}$ NAA/liter and $0.1 \mathrm{mg}$ kinetin/liter (embryo development medium). Embryos that converted to plantlets were rooted on MS medium with $2 \%$ glucose.

All culture media, except as noted, contained $3 \%$ sucrose, were solidified with $0.9 \%$ Bacto agar, and were adjusted to $\mathrm{pH} 5.9$ before autoclaving. Callus initiation and embryo induction cultures were incubated in the 


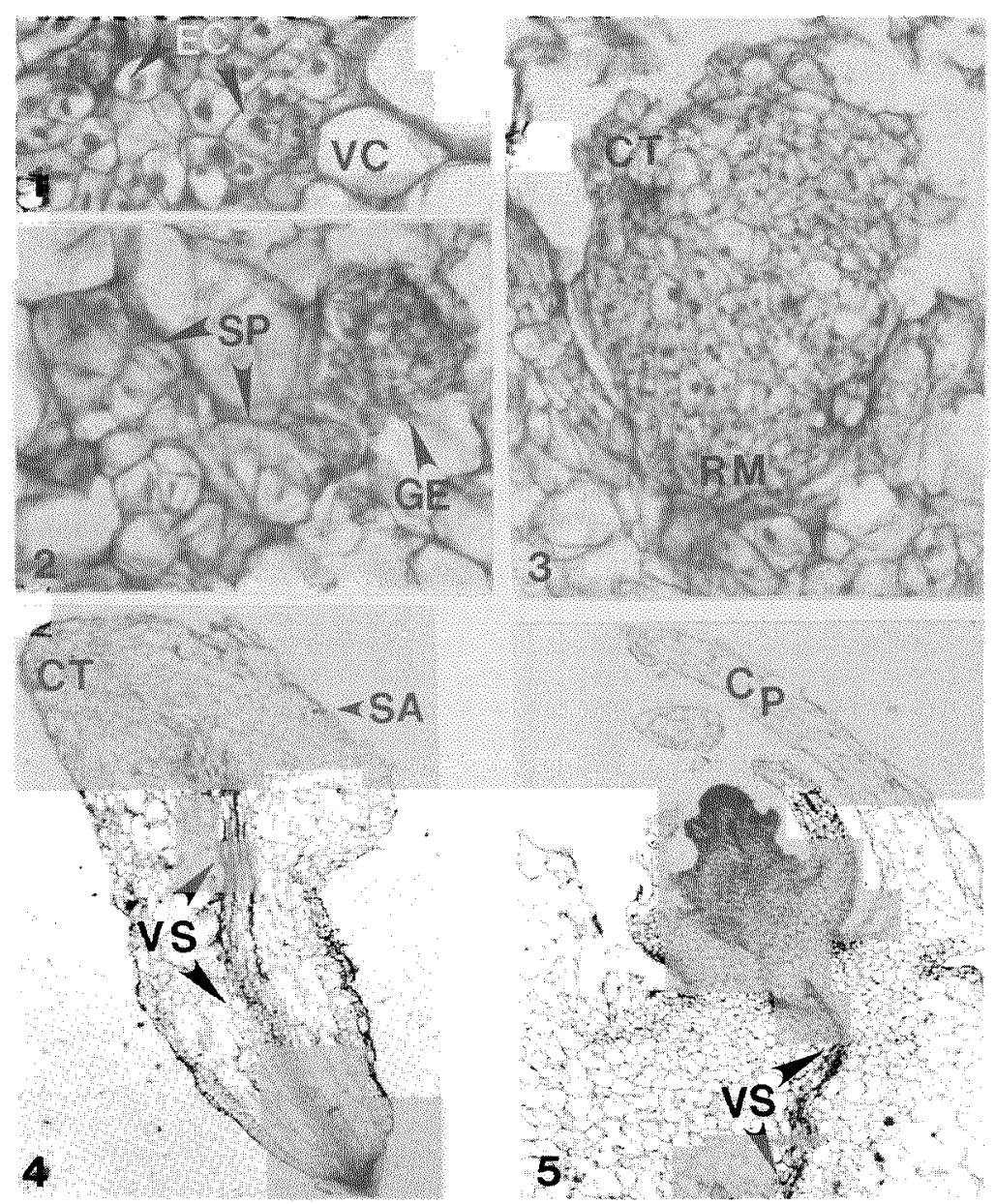

Figs. 1-5. Developmental sequence of somatic embryos. (1) Callus on embryo induction medium showing early formation of embryonic cells (EC), surrounded by large vacuolated cells $(\mathrm{VC})(\times 620)$. (2) Early globular stage embryo on embryo induction medium. Note the large suspensor cells (SP) and globular embryo (GE) $(\times 310)$. (3) Bipolar embryo on embryo development medium. Note cotyledon region $(\mathrm{CT})$ and root meristem $(\mathrm{RM})(\times 160)$. (4) Embryo in late maturation stage. Note the cotyledon (CT), vascular system (VS) with xylem and phloem cells, and shoot apex region (SA) $(\times 16.5)$. (5) Longitudinal section through shoot apex of mature somatic embryo. Note the vascular system (VS) and coleoptile (CP) $(\times 78)$.

dark at $26 \mathrm{C}$ and during subculture under a 16-h photoperiod $\left(16 \mu \mathrm{mol} \cdot \mathrm{m}^{-2} \cdot \mathrm{s}^{-1}\right)$ from cool-white fluorescent bulbs.

For histological studies, 12 to 18 tissue samples (1.5- to 2-cm diameter) were taken after 2 and 4 weeks on embryo induction medium, and after 1, 2, 4, and 6 weeks on embryo development medium. These samples were embedded in paraffin following fixation in Craf III solution (Sass, 1958), dehydration in a tertiary butanol series, and clearing in an ethanol-xylol series (Berlyn and Miksche, 1976). Sections were cut at 12 to $15 \mu \mathrm{m}$ using a rotary microtome and were affixed to glass slides (smeared with Haupt's adhesive) on a warming plate, 40C. Paraffin was removed from sections using xylol, 5 to $20 \mathrm{~min}$. Sections were stained for $48 \mathrm{~h}$ with safranin and fast green, washed and cleared using ethanol and xylol, and mounted in Canada balsam (Berlyn and Miksche, 1976; Sass, 1958).

Callus on embryo induction medium was yellowish and friable and comprised of many discrete groups of small embryonic cells surrounded by large vacuolated cells (Fig. 1).
In contrast to the surrounding cells, the embryonic cells had a dense cytoplasm, conspicuous nucleus, and thin cell wall (Fig. 1), characteristic of early somatic embryogenesis in other monocot species (Ho and Vasil, 1983). After 4 weeks on embryo induction medium, callus contained embryos in the early (Fig. 2) globular stages.

Somatic embryos in the early globular stage consisted of a spherical region of eight to 64 small cytoplasmically dense cells attached to an elongated region of six to 14 large cells (Fig. 2). This formation resembles the pattern known for early stage zygotic embryos of various monocot species where the globular embryo is attached to suspensor cells (Raghavan, 1976, 1986).

Within 2 weeks on embryo development medium, the globular embryos developed a bipolar shape (Fig. 3). Embryos at this stage were comprised of cells larger (2- to 6-fold) than those at the globular stage. Bipolar embryos had an extended upper region that formed the cotyledon and the epicotyl, and a lower region that formed the radicle (Fig. $3)$.
Mature embryos were opaque and attained a 4- to 7-mm length within 4 to 6 weeks on embryo development medium (Fig. 4). They possessed a distinct cotyledon, shoot apex, and an elongated radicle. In addition, vascular tissue was apparent interconnecting the root and shoot meristems (Fig. 4). Before plantlet formation, the shoot apex of mature embryos was fully differentiated and enclosed with a large coleoptile (Fig. 5). This coleoptile resembled the coleoptile that covers the shoot apex in zygotic embryos of asparagus (Riviere, 1973) and other monocotyledon species (Raghavan, 1976).

Many mature somatic embryos (Figs. 6 and 7) resembled asparagus zygotic embryos (Fig. 9), having a banana or crescent shape with an elongated cotyledon and a lateral shoot apex (Esau, 1977; Riviere, 1973). Other mature somatic embryos had a short but wide cotyledon (Fig. 8) that did not resemble the asparagus zygotic embryo, but that is typical of other monocot species (Raghavan, 1976, 1986). Irrespective of shape, both types of somatic embryos converted in equal frequencies to plantlets within 4 to 10 weeks on embryo development medium (Fig. 10).

The mature somatic embryos converted to plantlets with a distinct cotyledon residue at the shoot and root junction and a secondary lateral shoot apex adjacent to the primary shoot (Fig. 10). This pattern resembled the asparagus seed embryo during germination where the lower regions of the cotyledon and the epicotyl elongate to push the radicle and the apex out of the seed coat (Eaau, 1977; Riviere, 1973) and a secondary shoot apex appears while the primary shoot emerges (Riviere, 1973). Following conversion, single plantlets (Fig. 10) produced an extensive root system and new fern growth within 4 weeks on MS with $2 \%$ glucose in culture tubes.

\section{Literature Cited}

Berlyn, G.P, and J.P. Miksche. 1976. Botanical microtechnique and cytochemistry. The Iowa State Univ. Press, Ames.

Bui Dang Ha, D., B. Norreel, and A. Masset. 1975. Regeneration of Asparagus officinalis L. through callus cultures derived from protoplasts. J. Expt. Bot. 26:263-270.

Esau, K. 1977. Anatomy of seed plants. Wiley, New York

Ho, W.J. and I.K. Vasil. 1983. Somatic embryogenesis in sugarcane (Saccharum officinarum L.) I. The morphology and physiology of callus formation and the ontogeny of somatic embryos. Protoplasm 118:169-180.

Levi, A. and K.C. Sink. 1991. Somatic embryogenesis in asparagus: The role of explants and growth regulators. Plant Cell Rptr. 10:71-75.

Murashige, T. and F. Skoog. 1962. A revised medium for rapid growth and bioassays with tobacco tissue cultures. Physiol. Plantarum 15:473497.

Raghavan, V. 1976. Experimental embryogenesis in vascular plants. Academic, London.

Raghavan, V. 1986. Embryogenesis in angiosperms. Cambridge Univ. Press, New York.

Reuther, G. 1977. Adventitious organ formation and somatic embryogenesis in callus of asparagus and iris and its possible application. Acta Hort. 78:217-224. 

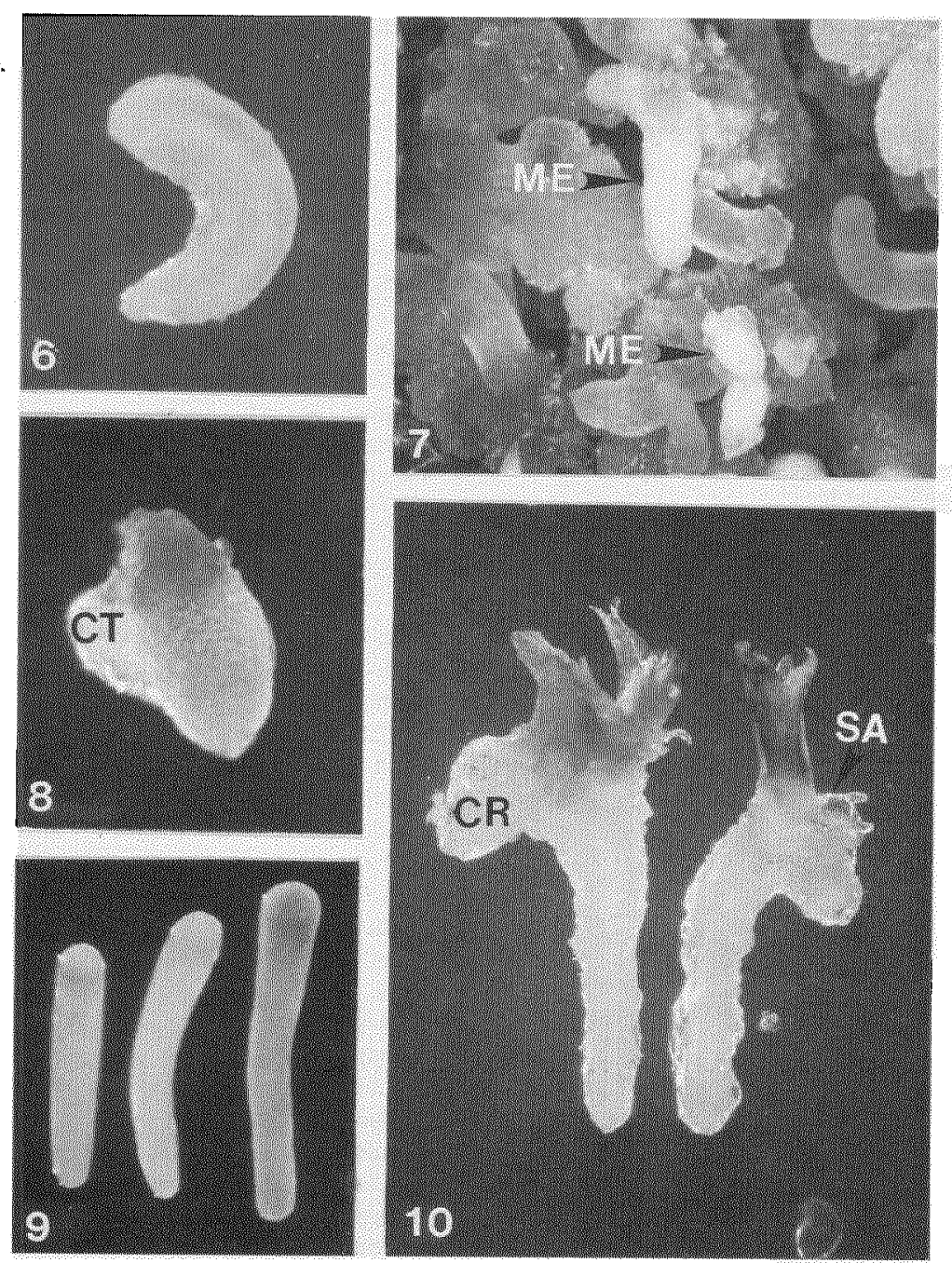

Figs. 6-10. (6) Elongated somatic embryo, after 4 weeks on embryo development medium $(\times 14)$ (7) Embryogenic callus after 4 weeks on embryo development medium. Note mature embryos (ME) $(\times 4.5)$. (8) Short mature embryo with a wide cotyledon (CT), shoot apex, and a radicle after 6 weeks on embryo development medium $(\times 9.5)$. (9) Zygotic embryos 4 weeks after anthesis. $(\times 16)$ (10) Germinating somatic embryos showing cotyledon residue (CR), and lateral shoot apex (SA) with leaf primordia; after 6 weeks on embryo development medium $(\times 9.5)$.
Reuther, G. 1983. Asparagus, p. 211-242. In: R.W. Sharp, D.A. Evans, P.V. Ammirato, and Y. Yamada (eds.). Handbook of plant cell culture. vol. 2. Macmillan, New York.

Riviere, S. 1973. Les activités méristématiques durant l'ontogenése d'une plantule de monocotylédone à germination hypogée: l'Asparagus officinalis L. (Liliacees). C.R. Acad. Sci. Paris 277:293-296.

Sass, J.E. 1958. Botanical microtechnique. The Iowa State Univ. Press, Ames.

Steward, F.C. and M.O. Mapes. 1971. Morphogenesis and plant propagation in aseptic cultures of asparagus. Bot. Gaz. 133:70-79.

Wilmar, C. and M. Hellendoom. 1968. Growth and morphogenesis of asparagus cells cultured in vitro. Nature (London) 217:369-370.

Yang, H.J. and W.J. Clore. 1973. Aerial crowns in Asparagus ofinialis L. HortSciencc 8:33. 